\title{
Rendering the loss of strength in dry concretes with addition of milled asphalt through microscopic analysis
}

\section{Interpretação da perda de resistência em concretos secos com incorporação de fresados asfálticos com apoio de análise microscópica}
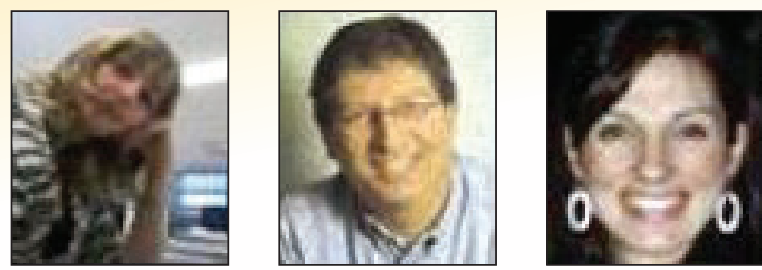

T. SACHET a tais.sachet@lenc.com.br

J.T. BALBO b jotbalbo@usp.br

F.T. BONSEMBIANTE c francieli.tiecher@ufrgs.br

\begin{abstract}
Milled asphalt removed from old pavement carpets requires tenable handling easily reachable through its incorporation within other paving materials. This work deals with the effects of such incorporation to dry compacted concretes. Fine, intermediate, coarse and whole portions of milled asphalts were blended to a reference concrete. Mechanical tests disclosed remarkable losses on its strengths and modulus of elasticity; for the stereoscope and scanning microscopy pointed out impaired transition zones between the cement paste and the milled aggregates involved by thin asphalt films. Nevertheless, the mechanical results shown that the concretes with incorporated milled asphalt aggregates are suitable for use in pavement layers as bases and sub-bases even with reduced mechanical parameters.
\end{abstract}

Keywords: dry concrete, milled asphalt, strength, modulus of elasticity, microscopy, aggregate-paste interface.

\section{Resumo}

Os fresados asfálticos são resultantes da fresagem de revestimentos asfálticos, sendo desejável seu manejo sustentável, o que pode ser alcançado incorporando-os em outros materiais de pavimentação. Neste trabalho foram estudados os efeitos de sua incorporação em concretos secos (compactados). Frações de fresados nas faixas de miúdos, pedriscos, britas e sua fração total foram incorporadas ao concreto de referência. Ensaios mecânicos mostraram relevantes perdas de resistência e de módulo de elasticidade desses concretos incorporando fresados. Análises com lupa estereoscópica e microscópio eletrônico de varredura mostraram que a interface entre o agregado fresado e a pasta de cimento foi prejudicada pela presença do filme asfáltico envolvendo os fresados. Muito embora a incorporação dos fresados ao concreto seco reduza a sua resistência bem como outros parâmetros mecânicos, o concreto resultante pode ainda assim pode ser utilizado como base e sub-base de pavimentos.

Palavras-chave: concreto seco, fresados asfálticos, resistência, módulo de elasticidade, microscopia, interface pasta-agregado. 


\section{Introduction}

The production of milled asphalt (also called reclaimed asphalt pavement, RAP) from restoration of roads and highways, is quite relevant [1], requiring specific policies regarding the disposal of these materials. RAPs are the result of asphalt coating dismantling by milling drums with pins. Its typical features are the presence of an asphalt film involving fractions of aggregates and clumps of particles resulting from the agglomeration of different diameters by asphalt binder that were not fractionated during its removal by milling. Although in the most technologically developed countries RAP are the basic material for recycling aged asphalt mixtures, there are numerous reports on previous studies that assessed the consequences of having it included as an alternative application in plastic concretes [2, $3,4,5]$, checking its effects in the mixture, given its embedding in con- crete for paving. Essentially of laboratorial nature, these investigations gave rise to a study on the concretes with the incorporation of RAP, by evaluating mechanical parameters. In all these previous studies, it was found that any amount of milled added to the concrete causes a reduction in its strength and in its modulus of elasticity.

In a previously published study with partial results, the effects of incorporating RAP into dry concrete for paving, usually called by roller compacted concrete [6], were presented. According to the American Concrete Institute [7] the roller compacted concrete (RCC) is a concrete of a very dry consistency, in a way that its density can be easily accomplished by metal rollers. Another peculiarity is that in the RCC, the cement consumption is generally lower than that of plastic concrete used in concrete paving. The RCC has a wide application in asphalt pavements and concrete pavements as base, with important advantages over other materials such as

\section{Figure 1 - Grading curves of Pittman \& Ragan (1998) and reference RCC}
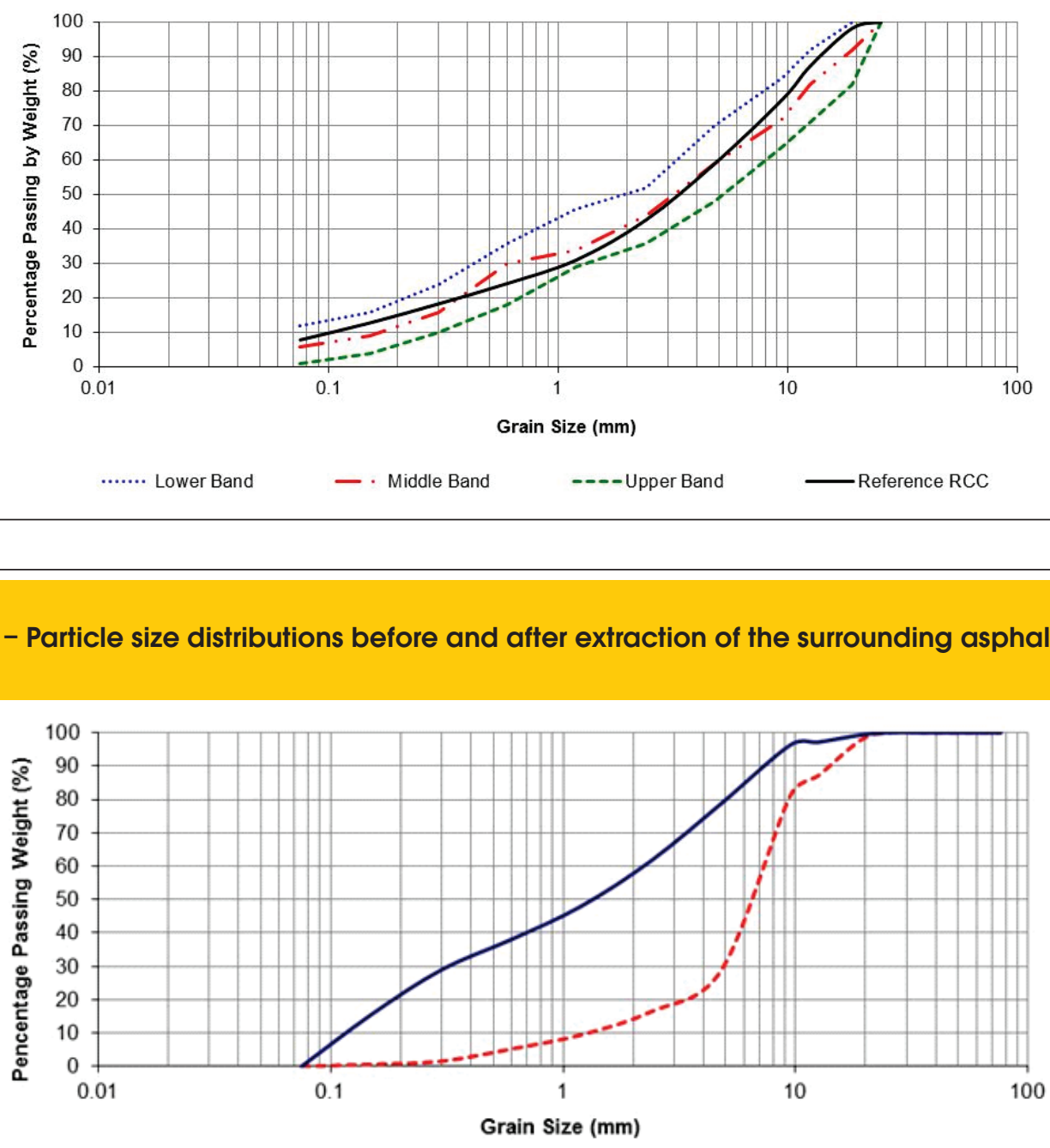

--- RAP before asphalt extraction $\quad$ RAP after asphalt extraction 


\section{Figure 3 - Sieved fractions of RAP: stone dust, medium stone and coarse stone (right to left)}
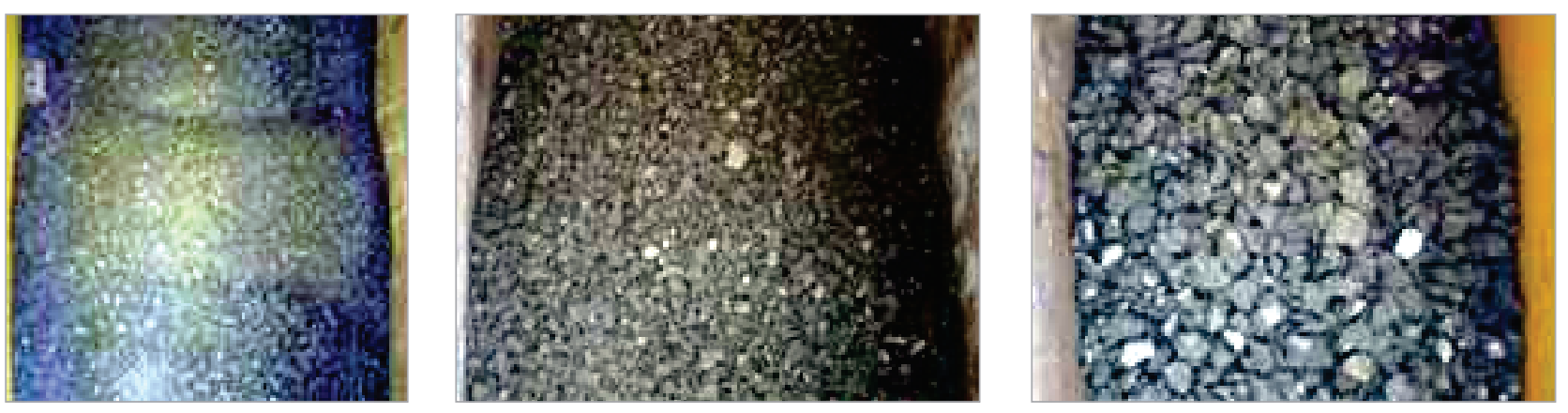

cement treated crushed stone and soil-cement mixtures.

Mixtures of RCC incorporating the RAP presented herein were subjected to microscopic analysis through scan electronic microscopy (SEM) and optics microscopy, with the purpose of assessing the presence of asphalt films over aggregates and damaged areas of transition, as to elucidate the losses occurring in terms of strength and elasticity modulus in relation to the dry concrete reference used in the study.

\section{Types of RCC studied in laboratory and its constituents}

The laboratory investigation on the effects of milled incorporation into the RCC had as a reference the assembly mixtures with particle size distribution according to the recommendations of Pittman and Ragan [8], who studied the aspects related to the shrinkage of these materials, with the purpose of obtaining less retractable mixtures. This particle size distributions are shown in Figure 1, as upper, middle and lower band distributions; along with these bands, it is determined the particle size range adopted for the reference mixture, with virgin aggregates and without incorporation of RAP, well graded and tending to the indicated average curve.
For the preparation of the mixtures, crushed materials (crushed stone size \#1- 9.5 to $19 \mathrm{~mm}$-, medium crushed stone -2.4 to $9.5 \mathrm{~mm}$, and stone dust - less tha $2.4 \mathrm{~mm}$ ) from the Quarry Cantareira (in São Paulo City), clean river sand and the hydraulic binder CP III-RS-40 (NBR 5735) were used. The kneading water was the drinkable water provided from São Paulo distribution network. The RAP was achieved in the Anchieta Highway, km 39, in the direction to the Coastline of São Paulo State, at the time of its extraction with a milling machine, where Figure 2 shows its particle size distributions before and after extraction of the surrounding asphalt binder. The RAP would be used, of course, without extracting the surrounding asphalt binder and, therefore, with grain distribution tending more to uniformity.

Such RAP were then ranked and separated into three ranges of diameters: big or crushed stone \#1 (9.5 to $19 \mathrm{~mm}$ ), medium or crushed rock (2.4 to $9.5 \mathrm{~mm}$ ) and the fine fraction - sand or stone dust - (with less than $2.4 \mathrm{~mm}$ ) diameter as shown in Figure 3. The replacement of natural aggregates with RAP was performed as to compose four mixtures as shown in Table 1. The reference RCC is the RCC1; the RCC2 is alternative for employing river sand in their fine fraction instead of stone dust; mixtures with RAP are designated by RCC1, followed by the abbreviation for the fraction of incorporated RAP (the sand fraction is called FA and so on).

Table 1 - Size distribution of RCC mixtures (by weight)

\begin{tabular}{|c|c|c|c|}
\hline Mixture & Composition & $\begin{array}{l}\text { Natural } \\
\text { aggregates (\%) }\end{array}$ & $\begin{array}{l}\text { Milled } \\
\text { aggregates (\%) }\end{array}$ \\
\hline $\mathrm{RCCl}$ & Reference RCC using stone & 100 & - \\
\hline $\mathrm{RCC} 2$ & dusty or industrial sand & 100 & - \\
\hline RCCl-FS & $\begin{array}{l}\text { RCC using river sandRCC with } 100 \% \text { of } \\
\text { replacement of fine fraction }(<2,4 \mathrm{~mm}) \text { by fine RAP }\end{array}$ & 63 & 37 \\
\hline RCCl-FM & $\begin{array}{l}\text { RCC with } 100 \% \text { of replacement of medium } \\
\text { fraction }(2,4 \text { to } 9.5 \mathrm{~mm}) \text { by medium RAP }\end{array}$ & 61 & 39 \\
\hline $\mathrm{RCCl-FC}$ & $\begin{array}{l}\text { RCC with } 100 \% \text { of replacement of coarse fraction } \\
(9.5 \text { to } 19 \mathrm{~mm}) \text { by coarse RAP }\end{array}$ & 76 & 24 \\
\hline $\mathrm{RCCl-FT}$ & $\begin{array}{c}\text { RCC with } 50 \% \text { replacement of its total fraction by } \\
50 \% \text { of RAP total fraction }\end{array}$ & 50 & 50 \\
\hline
\end{tabular}


Rendering the loss of strength in dry concretes with addition of milled asphalt through microscopic analysis

Table 2 - Virgin aggregates physical indexes

\begin{tabular}{|ccccc|}
\hline Index & Natural sand & Stone dust & Medium stone & Coarse stone \\
\hline Maximum diameter $(\mathrm{mm})$ & 4.8 & 2.4 & 9.5 & 19 \\
Fineness modulus & 4.018 & 3.507 & 6.814 & 7.967 \\
Bulk density $\left(\mathrm{kg} / \mathrm{cm}^{3}\right)$ & 2,632 & 2,620 & 2,708 & 2,682 \\
Unitarian mass $\left(\mathrm{kg} / \mathrm{cm}^{3}\right)$ & 1,590 & 1,630 & 1,390 & 1,430 \\
\hline
\end{tabular}

In order to RCC1 present an indirect tensile strength $\left(f_{t, s p}\right)$ of $2.5 \mathrm{~N} /$ $\mathrm{mm}^{2}$, previous proportioning studies resulted in cement consumption of $100 \mathrm{~kg} / \mathrm{m}^{3}$ [6]. RCC compaction was done in cylindrical molds (100 $\times 200 \mathrm{~mm})$ and prismatic molds $(100 \times 100 \times 400 \mathrm{~mm})$. For cylindrical

Table 3 - Physical indexes for the RAP

\begin{tabular}{|ccc|} 
Index & $\begin{array}{c}\text { Coarse } \\
\text { RAP* }\end{array}$ & $\begin{array}{c}\text { Fine } \\
\text { RAP* }\end{array}$ \\
\hline Maximum diameter $(\mathrm{mm})$ & 19.0 & 2.4 \\
Grain apparent & 2,288 & 2,157 \\
density $\left(\mathrm{g} / \mathrm{cm}^{3}\right)$ & 1.32 & - \\
Absorption $(\%)$ & 0.78 & 4.43 \\
Fineness modulus & & \\
* without asphalt extraction & & \\
\hline
\end{tabular}

specimens, molding was carried out in five layers with 24 blows per layer. In prismatic molds, molding consisted of two compacted layers with 154 strokes each. The compaction energy used was to Normal Proctor with $2.5 \mathrm{~kg}$ hammer and drop height of $300 \mathrm{~mm}$ (NBR 7182). Tables 2 and 3 show some physical characteristics of the aggregates used in the studies. In Table 4 the compaction indexes for dry concrete mixtures studied are given, and the most significant moisture increases were observed for RCC incorporating sand fraction and total fraction; for both cases, there are also more relevant drops in the density of concrete. Anyway, any incorporation of RAP caused a reduction in the density of the mixtures, which is partly explained by the presence of asphalt binders (with unit density).

\section{Testing procedures}

After the curing process in wet chamber, the specimens were submitted, at 7 and at 35 days of age, to the following mechanical tests:

- Diametral compression test or Split test according to the NBR 7222 [9] carried out to determine the indirect tensile strength and modulus of elasticity;

- Bending or Flexural strength test according to the ASTM-C78-08 [10] carried out to determine the tensile strength in bending and elasticity module to measure the arrow in the middle of the span of joist; the assay was performed with a cleaver.

Microscopic tests, the main object of this article and its discussion, had the purpose of observing the porosity of the concrete, the possible microstructural changes by the presence of RAP, and mainly, the observation of possible flaws in the interface (transition zone) between the milled aggregate with bitumen and cement paste. These observations were made by scanning electron microscopy (SEM), by secondary electrons (SE) and backscattered (BSE), as well as with the use of a stereomicroscope. These tests were performed

\begin{tabular}{|cccc|}
\hline \multicolumn{4}{|c|}{ Table $4 \begin{array}{c}\text { - Optimum moisture content } \\
\text { for the studied RCC }\end{array}$} \\
Concrete & Moisture (\%) & a/c ratio & $\begin{array}{c}\gamma_{\text {as }} \\
\left(\mathrm{kg} / \mathrm{m}^{3}\right)\end{array}$ \\
\hline RCC1 & 7.15 & 1.137 & 2,268 \\
RCC2 & 8.05 & 1.196 & 2,258 \\
RCC1-FS & 8.40 & 1.334 & 2,046 \\
RCC1-FM & 7.30 & 1.159 & 2,130 \\
RCC1-FC & 7.50 & 1.175 & 2,148 \\
RCC1-FT & 8.20 & 1.302 & 2,048 \\
\hline
\end{tabular}

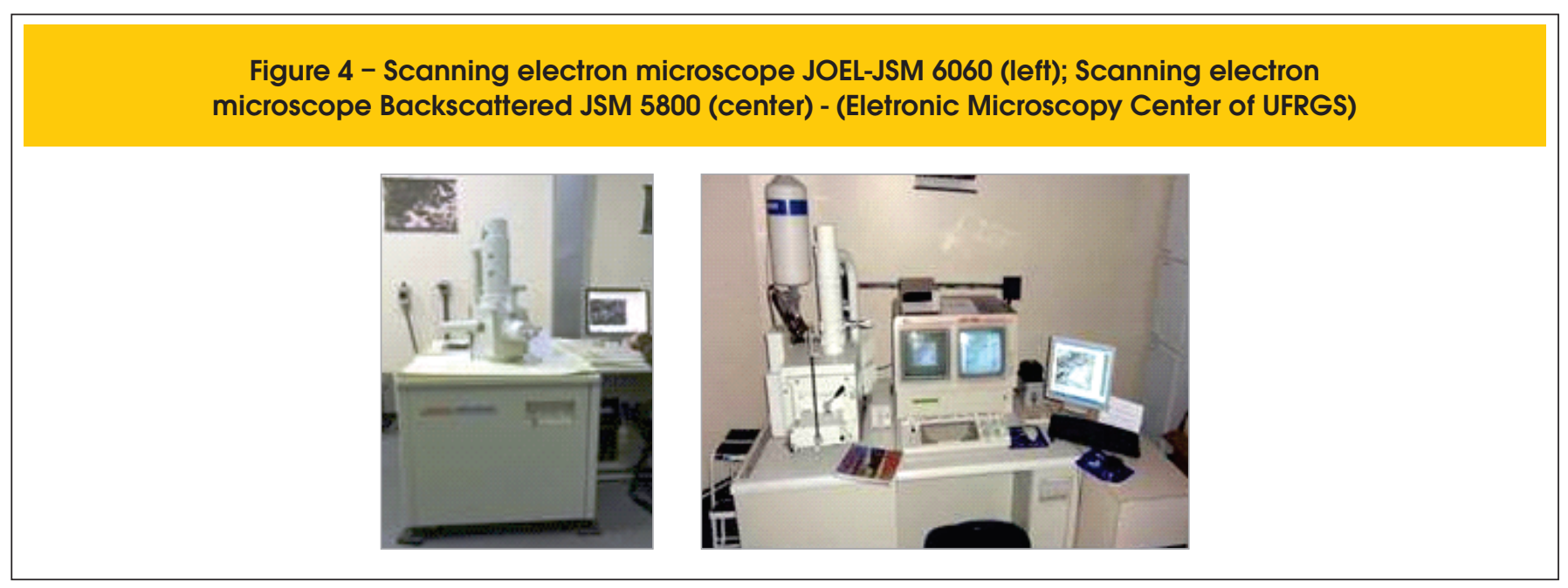


Figure 5 - Observations in a stereomicroscope Olympus BX51M
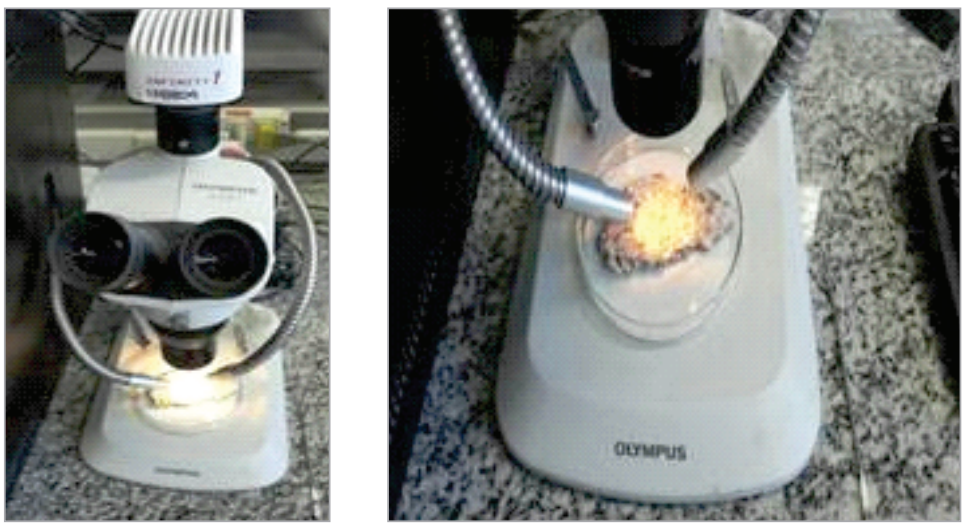

at the Universidade Federal do Rio Grande do Sul (URFGS) at the Laboratório de Cerâmica (LACER) of the UFRGS. A brief description of the equipment and methods are presented in the following.

For observation by SEM SE (Secondary Electron), fragments of six samples from the RCC were used. Samples were previously dried in oven and metallized with gold fog. In the observations of secondary electrons, the purpose was to observe the morphology of the samples through their topographic reading. The microscope used for this analysis was a JEOL JSM - 6060 model (Figure 4) that operates between 0.3 to $30 \mathrm{kV}$, with point image resolution of $3.5 \mathrm{~nm}$, a magnification range of $18 \mathrm{X}$ at $300,000 \mathrm{X}$, motorized goniometric stage of 5 axes, eccentric in all positions, with an tilt of samples from -10 to $+90^{\circ}$, and $360^{\circ}$ rotation.

For analyzes using SEM BSE (Backscattered Electrons), samples were metallized with carbon fog. The microscope used was a JEOL JSM - 5800 model (Figure 4). These samples were obtained by cutting specimens to obtain pellets with about $5 \mathrm{~mm}$ thickness and 10 $\mathrm{mm}$ sides. The images obtained by backscattered electrons show changes in the chemical composition of the features observed, through changes in grayscale. Therefore, it is important that the pastille is analyzed as flat as possible. This microscope operates in a range from 0.3 to $30 \mathrm{kV}$, point image resolution of $3.5 \mathrm{~nm}$, magnifying range of $18 \times 300,000 \times$, a 5-stage-axis motorized goniometric, eccentric in all positions $(X=125 \mathrm{~mm}, Y=100 \mathrm{~mm}, Z=43 \mathrm{~mm})$, sample tilting from $-10^{\circ}$ to $+90^{\circ}$ and $360^{\circ}$ rotation, a vacuum prechamber, and with the possibility of having a qualitative chemical analysis through spectroscopy and dispersive energy (EDS).
The observations made in the stereoscopic magnifying glass Olympus BX51M (Figure 5), were performed to assess the porosity of the samples and the bond between the cement paste and the milled aggregate surfaces.

\section{Results presentation and its analysis}

\subsection{Mechanical tests}

Indirect tensile strength $\left(\mathrm{f}_{\mathrm{ctsp}}\right)$ of concretes is showed in Table 5 (for all results the mean values, standard deviation and coefficient of variation are shown), where their specific gravities are also indicated. The decreasing in the values of the density of the mixtures with RAP is evident in the results, where the concrete incorporating fine or total RAP fractions had the greatest reductions. Reduction in $\mathrm{f}_{\mathrm{ctsp}}$ was very important for RAP sand fraction incorporation, reaching an average over $60 \%$; full RAP fraction incorporation, in turn, had more than $50 \%$ reduction. Indirect tensile strength was in all cases fairly affected. Results show to be consistent with the compaction moistures that were higher for RCC1-FS and RCC1-FT.

It is important to point out that significant differences were observed in the way samples had ruptures when incorporation of RAP was present. Concrete with no milled had abrupt and conical type fractures, with cylinder splitting, characterized by the disruption of the mortar. The samples with RAP had more subtle fractures; cylinders were not split and they kept on having some charge after the initial fracture (Figure 6). The ex-

Table 5 - Values for indirect tensile strength of RCC

\begin{tabular}{|c|c|c|c|c|c|c|c|}
\hline Concrete & $\mathrm{n}$ & Age (days) & $\gamma_{\text {apparent }}\left(\mathrm{kg} / \mathrm{m}^{3}\right)$ & $\mathrm{f}_{\mathrm{ct}, \mathrm{sp}}(\mathrm{MPa})$ & sd (MPa) & cv (\%) & $\Delta \mathrm{f}_{\mathrm{t}, \mathrm{sp}}(\%)$ \\
\hline $\mathrm{RCCl}$ & 3 & 7 & 2,425 & 1.15 & 0.07 & 4.7 & - \\
\hline $\mathrm{RCCl}$ & 6 & 35 & 2,417 & 2.45 & 0.08 & 3.4 & - \\
\hline $\mathrm{RCC} 2$ & 3 & 7 & 2,401 & 1.19 & 0.04 & 3.7 & 3.5 \\
\hline $\mathrm{RCC} 2$ & 6 & 35 & 2,347 & 2.06 & 0.05 & 2.6 & -15.9 \\
\hline $\mathrm{RCCl}-\mathrm{FS}$ & 6 & 35 & 2,248 & 0.96 & 0.04 & 4.1 & -60.8 \\
\hline RCCl-FM & 6 & 35 & 2,310 & 1.64 & 0.10 & 6.1 & -33.1 \\
\hline $\mathrm{RCCl}-\mathrm{FC}$ & 6 & 35 & 2,302 & 1.48 & 0.09 & 6.6 & -39.6 \\
\hline RCCl-FT & 6 & 35 & 2,285 & 1.21 & 0.07 & 6.3 & -50.6 \\
\hline
\end{tabular}




\section{Figure 6 - Indirect tensile tests on $\mathrm{RCCl}$ (left picture - abrupt fracture) and RCC-RAP (central and right picture- more subtle fractures)}
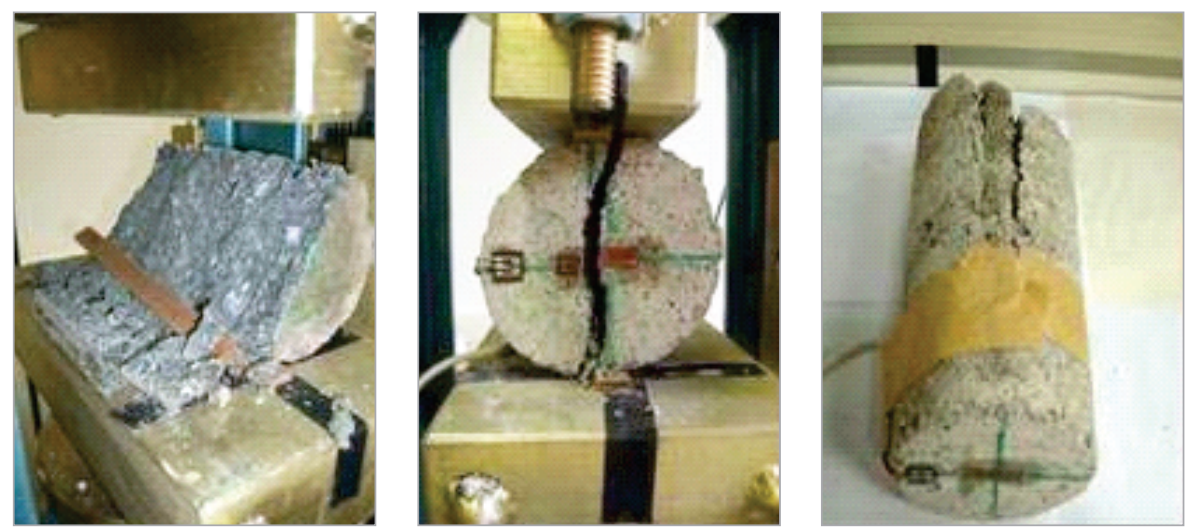

planation for this is the energy dissipation capacity of the concrete with asphalt milled, with a more ductile interface, and a more gradual way. It is important to emphasize that these dry concrete with milled incorporation show fracture strength and fracture energy by area of lower propagation, as seen with the same concrete concerned by Sachet et al.[11].

Test results for flexural strength $\left(\mathrm{f}_{\mathrm{ct}, \mathrm{f}}\right)$ are shown in Table 6 with the appropriate statistics already mentioned. During the tests, it was observed the presence of lumps in the mixture, from the union of coarse and fine grains with asphalt binder. Of course, such bind- ing weaken the concrete; these lumps cause a heterogeneous distribution of aggregates in the mixture, which can also promote the emergence of more fragile areas. It is observed that the $f_{c t, f}$ value (tests using one cleaver) is practically twice the value of $f_{c t, s p}$. Strength dropping was not equal for all concretes with different fractions of milled incorporated; sand and medium fractions resulted in lower decrease in the value of $f_{c t, f}$ while coarse fractions or the total fraction cause significant decreases in strength; therefore, there is no relation to the results observed for $f_{c t, s p}$.

Table 6 - Flexural strength results for RCC

\begin{tabular}{|c|c|c|c|c|c|c|c|}
\hline Concrete & $\mathrm{n}$ & Age (days) & $\gamma_{\text {apparent }}\left(\mathrm{kg} / \mathrm{m}^{3}\right)$ & $\mathrm{f}_{\mathrm{ct}, \mathrm{f}}(\mathrm{MPa})$ & sd (MPa) & cv (\%) & $\Delta f_{\mathrm{ct}, \mathrm{f}}(\%)$ \\
\hline $\mathrm{RCCl}$ & 3 & 7 & 2,446 & 2.31 & 0.04 & 1.7 & - \\
\hline $\mathrm{RCCl}$ & 6 & 35 & 2,321 & 4.23 & 0.32 & 8.7 & - \\
\hline $\mathrm{RCC} 2$ & 3 & 7 & 2,347 & 2.18 & 0.02 & 1.1 & -5.6 \\
\hline $\mathrm{RCC} 2$ & 6 & 35 & 2,292 & 3.91 & 0.24 & 6.2 & -7.6 \\
\hline RCCl-FS & 6 & 35 & 2,269 & 3.78 & 0.10 & 2.9 & -10.6 \\
\hline RCCl-FM & 6 & 35 & 2,296 & 3.80 & 0.32 & 8.9 & -10.2 \\
\hline RCCl-FC & 6 & 35 & 2,300 & 2.37 & 0.31 & 11.6 & -44.0 \\
\hline RCCl-FT & 6 & 35 & 2,164 & 2.55 & 0.21 & 8.6 & -39.7 \\
\hline
\end{tabular}

Table 7 - Modulus of elasticity of RCC in tensile.

\begin{tabular}{|ccccccc|} 
Concrete & $n$ & Age (days) & $E_{\text {sp }}(\mathrm{MPa})$ & sd $(\mathrm{MPa})$ & $\mathrm{cv}(\%)$ & $\Delta \mathrm{E}_{\mathrm{sp}}(\%)$ \\
RCCl & 6 & 35 & 30,403 & 6,176 & 20.3 & - \\
RCC2 & 6 & 35 & 19,029 & 6,285 & 33.0 & -37.4 \\
RCC1-FS & 3 & 35 & 10,534 & 2,743 & 26.0 & -65.4 \\
RCCl-FM & 2 & 35 & 7,685 & 1,569 & 20.4 & -74.7 \\
RCCl-FC & 3 & 35 & 18,920 & 2,351 & 12.4 & -37.8 \\
RCCl-FT & 6 & 35 & 7,038 & 1,570 & 22.3 & -76.9 \\
\hline
\end{tabular}


Table 8 - Flexural modulus of elasticity of RCC.

\begin{tabular}{|c|c|c|c|c|c|c|c|c|c|c|}
\hline Concrete & $n$ & $\begin{array}{l}\text { Idade } \\
\text { (dias) }\end{array}$ & $\begin{array}{c}E_{f 1} \\
(M P a)^{*}\end{array}$ & $\begin{array}{c}\text { sd } \\
(\mathrm{MPa})\end{array}$ & $\begin{array}{l}\text { CV } \\
(\%)\end{array}$ & $\begin{array}{l}\Delta \mathrm{E}_{11} \\
(\%)\end{array}$ & $\begin{array}{c}\mathrm{E}_{\mathrm{f2}} \\
(\mathrm{MPa})^{*} \text { * }\end{array}$ & $\begin{array}{c}\text { sd } \\
(\mathrm{MPa})\end{array}$ & $\begin{array}{l}\text { CV } \\
(\%)\end{array}$ & $\begin{array}{l}\Delta E_{12} \\
(\%)\end{array}$ \\
\hline CCRI & 6 & 35 & 24,313 & 3,494 & 14.4 & - & 28,632 & 4,373 & 15.3 & - \\
\hline CCR2 & 6 & 35 & 27,540 & 6,126 & 22.2 & 13.3 & 31,357 & 5,779 & 18.4 & 9.5 \\
\hline CCRI-FS & 6 & 35 & 13,394 & 3,216 & 24.0 & -44.9 & 17,888 & 5,594 & 31.3 & -37.5 \\
\hline CCRI-FM & 5 & 35 & 12,132 & 1,186 & 17.1 & -50.1 & 18,725 & 1,630 & 12.4 & -34.6 \\
\hline CCRI-FC & 5 & 35 & 10,416 & 922 & 8.9 & -57.2 & 13,925 & 2,402 & 21.3 & -51.4 \\
\hline CCR1-FT & 6 & 35 & 7,972 & 1,453 & 18.2 & -67.2 & 13,017 & 3,426 & 26.3 & -54.5 \\
\hline
\end{tabular}

Values of elasticity modulus of concrete containing RAP had significant decrease, as can be seen in Tables 7 and 8. At first, these reductions can be due to a greater amount of voids in concrete with heterogeneity and milled. These heterogeneities are configured in a weakening of the interface binding paste/milled aggregated, as well as in the presence of very flexible lumps in relation to its surroundings, and not adhered, which could be seen as voids in the internal structure of the concrete; it should also be understood that the coefficients of variation for this parameter indicate a reasonable dispersion in the results in most cases. The most significant declines are observed in the elasticity modulus measured during tests of diametrical compression with the stress curves versus strain. In all cases, concrete with total milled fraction incorporation were the most affected in relation to the reduction in the values of elasticity modulus. By making comparative judgments, the elasticity modulus values obtained with the incorporation of milled are indicative of a significant loss of a degree of freedom of materials; they start to behave, in values, as cement treated crushed stones, or even as soil-cement; even then, they can still be considered advantageous in relation to the paving materials aforementioned, because they have a higher strength, which ensures lower ratios of elasticity modulus/ strength. This is an indicative that alternatives of paving using RCC with RAP fractions in relation to traditional cement bases are real.

\subsection{Interpretation of microscopic analysis}

\subsubsection{Scanning electron microscopy (SE and BSE)}

The SEM was performed on all six mixtures studied. As expected, MEV analysis enabled to observe the transition zone between the cement aggregate and paste. Images obtained by the SEM SE of the RCC samples show the presence of characteristics formations of ettringite and other hydration products, pointing out that the hydration reactions actually occurred in the concrete containing RAP aggregates (Figure 7). However, due to the limitations of this analysis, it was possible to estimate that the amount of ettringite formed as equivalent to all concrete.

In Figure 7, it can be seen that the RCC1 concrete paste is dense and no homogeneous, and the mortar volume was not enough to involve the grains; it is typical of compacted concretes with low cement content. It was observed in this mixture the formation of hydrating products, $\mathrm{CSH}$ (calcium silicate hydrate) and ettringite.

\section{Figure 7 - Observations with MEV SE of RCC1 mixture.}
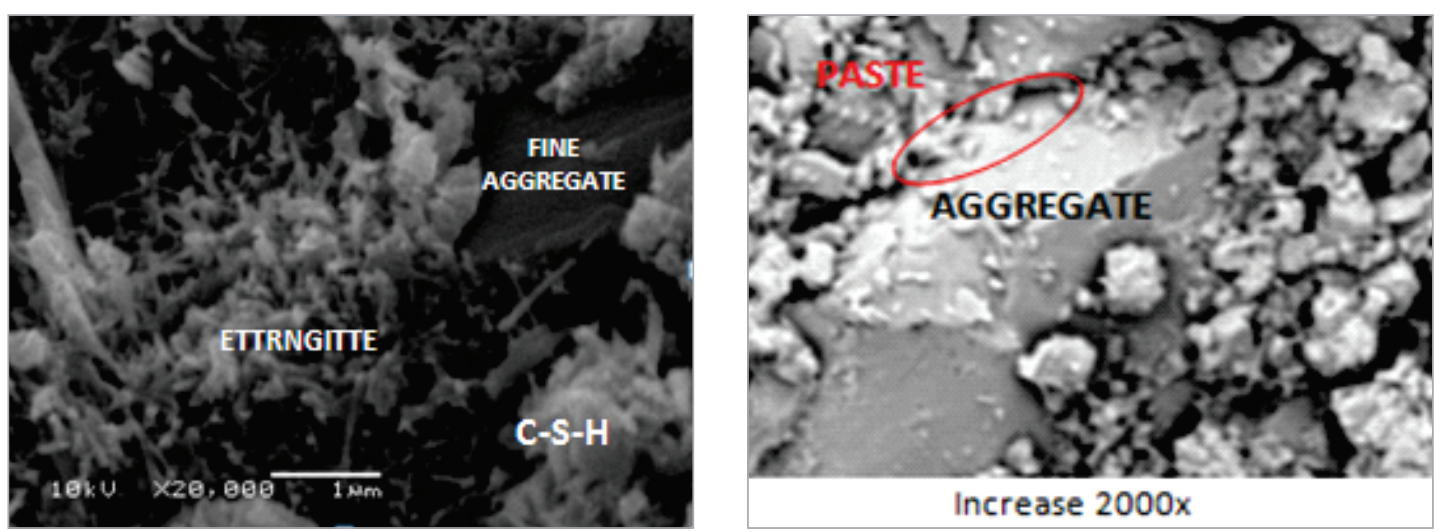
Observations on SEM BSE enabled to view some important as pects in the transition zone between the cement paste and the aggregates (Figure 8). Apparently, in all mixtures, there is a failure tendency in the binding between cement paste and aggregate; it stands on concrete RAP aggregates. Figure 8 also shows that in the RCC2, the amount of paste was also insufficient to involve the

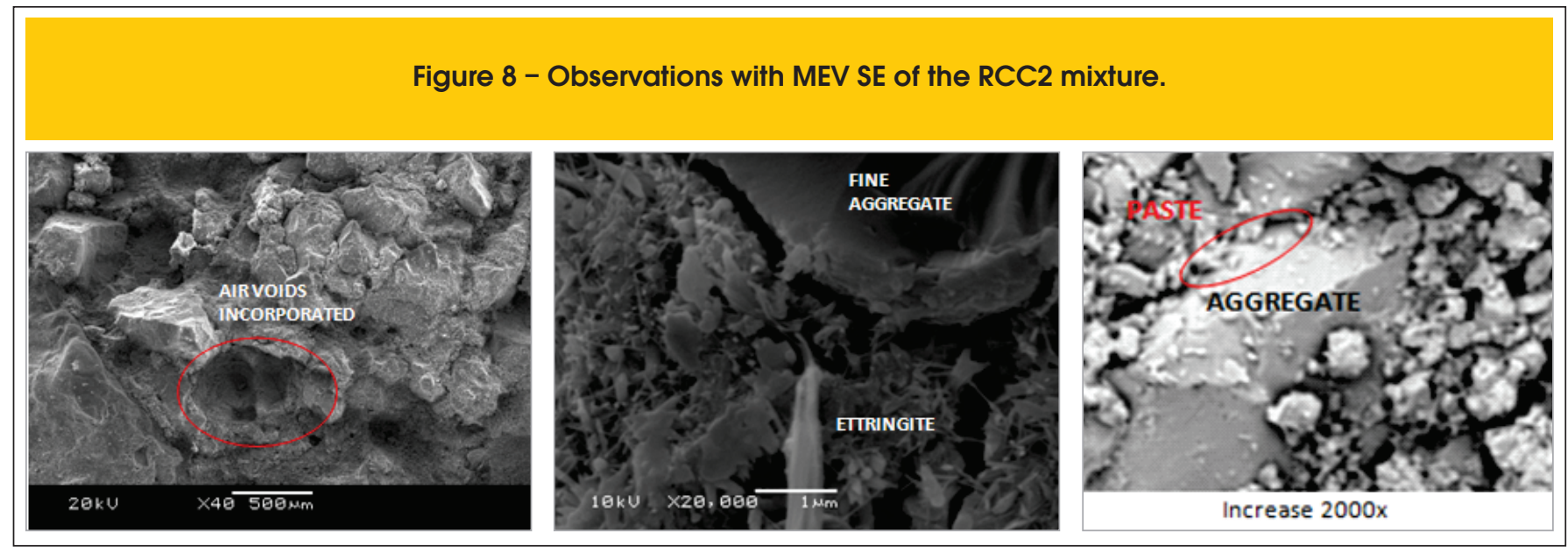

Figure 9 - Observations with MEV SE of mixture RCC1-FT
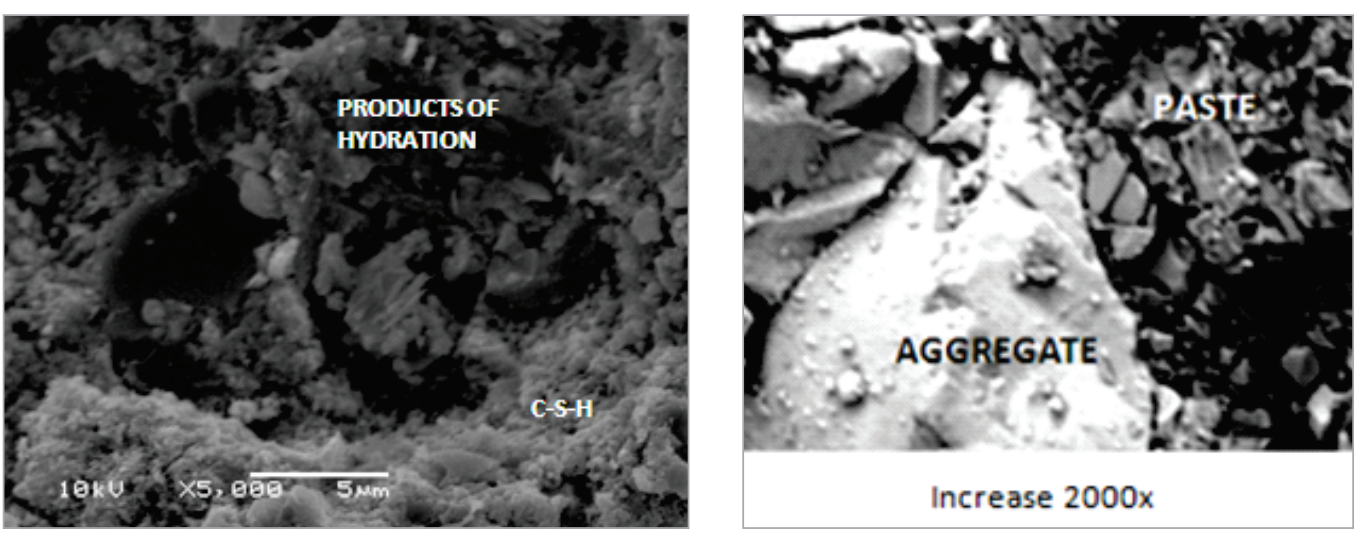

Increase 2000x

Figure 10 - Observations with MEV SE of mixture RCC1-FS.
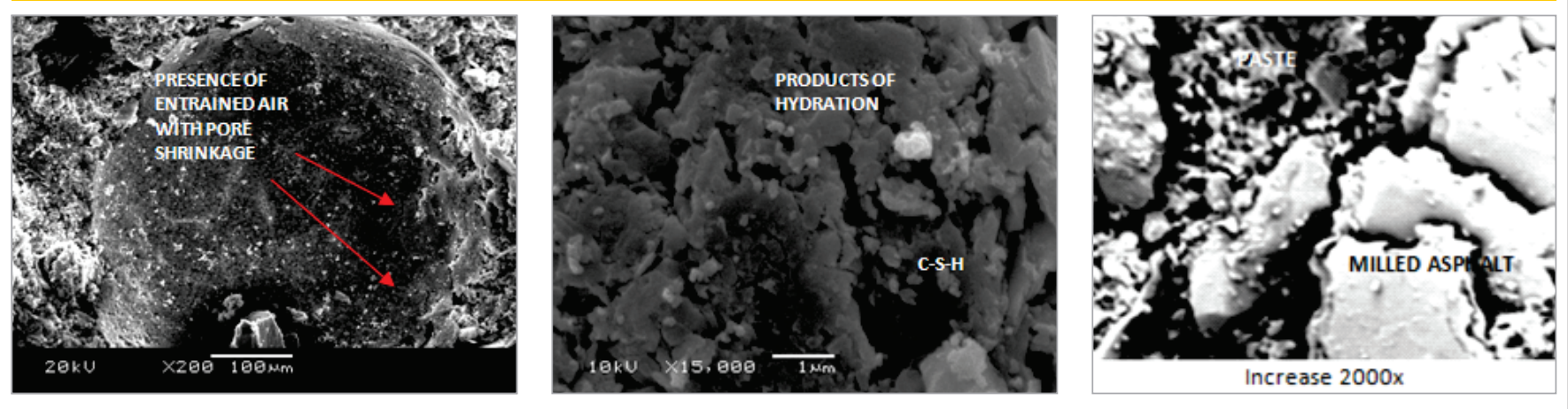
Figure 11 - Observations with MEV SE of mixture CCR 1-FM.
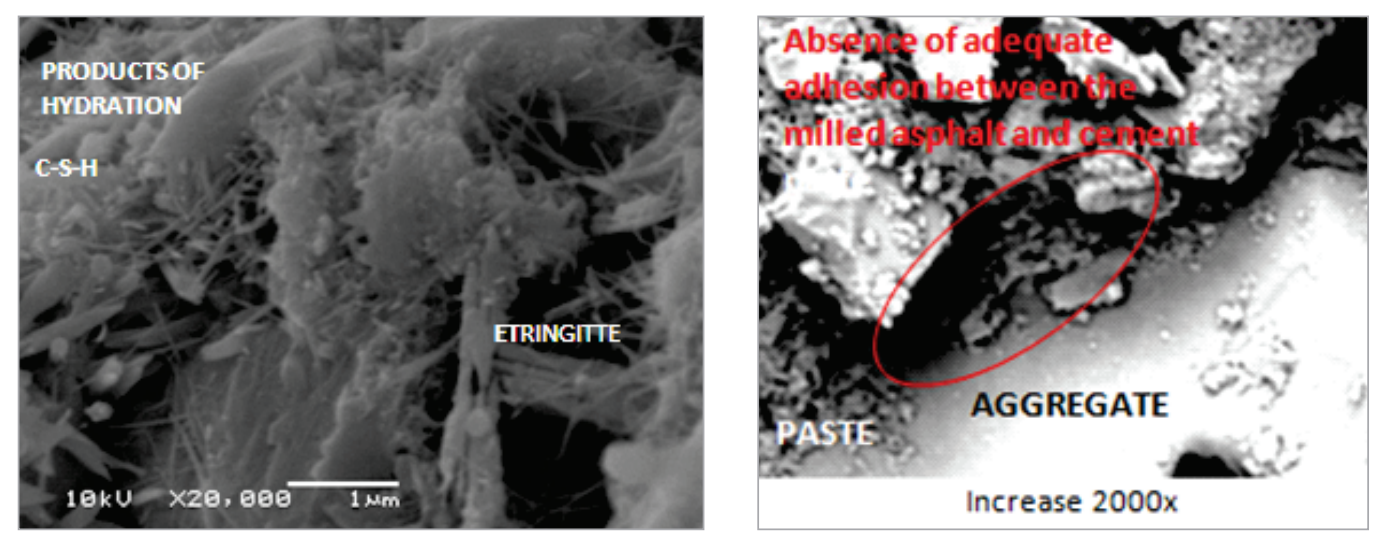

aggregates. It was possible to observe the existence of a large amount of typical air voids incorporated.

In the RCC1, it can be observed products of hydration, for example, the CSH. More importantly, it was found that this mixture is not homogeneous or dense (Figure 9). The images enabled to view microcracks in the transition zone between RAP aggregate and cement paste.

In Figure 10, which presents images of RCC1-FS mixture, the presence of entrained air with pore shrinkage cracks and formation of $\mathrm{C}_{3} \mathrm{~S}$ (tricalcium silicate), one of those responsible for the mixture strength. Microcracks were also observed in the transition zone between cement aggregates and paste.

In the micrographs of the RCC1-FM mixture, the presence of a heterogeneous paste is evident, as well as the formation of calcium monosulfoaluminate and CSH (Figure 11). Porosity is an important characteristic of this concrete, where the absence of adequate adhesion between the RAP and cement paste was observed.

The lack of adhesion is also visible in the RCC1-FC mixture (Figure 12). Calcium salts were identified in this case; the transition zone observed was not very dense, indicating a weaker region resulting in a concrete with less strength.

\subsubsection{Stereoscopic magnifier observations}

Observations by stereomicroscopy (Figures 13) showed no differences between the samples of concrete produced with natural aggregates (RCC1 and RCC2) and those produced with RAP aggregates. However, in a qualitative analysis, the images show to occur a better bind between natural aggregates and cement paste, i.e., the lower strength of milled aggregates of the concrete may be related to low mechanical adhesion of the RAP particles of the cement matrix. Therefore, it is believed that, with the increase in water/cement ratio (or moisture) of RCC with RAP incorporation, the low mechanical adhesion at interfaces is one of the causes, perhaps the most important, which contributed to the concrete with RAP aggregate have presented lower resistance values.

\section{Conclusions}

The laboratory study to evaluate the properties of compacted dry concretes (RCC) with RAP incorporation, enabled to achieve the following conclusions:

- RCC with RAP increased w/c ratio when compared to the ref-

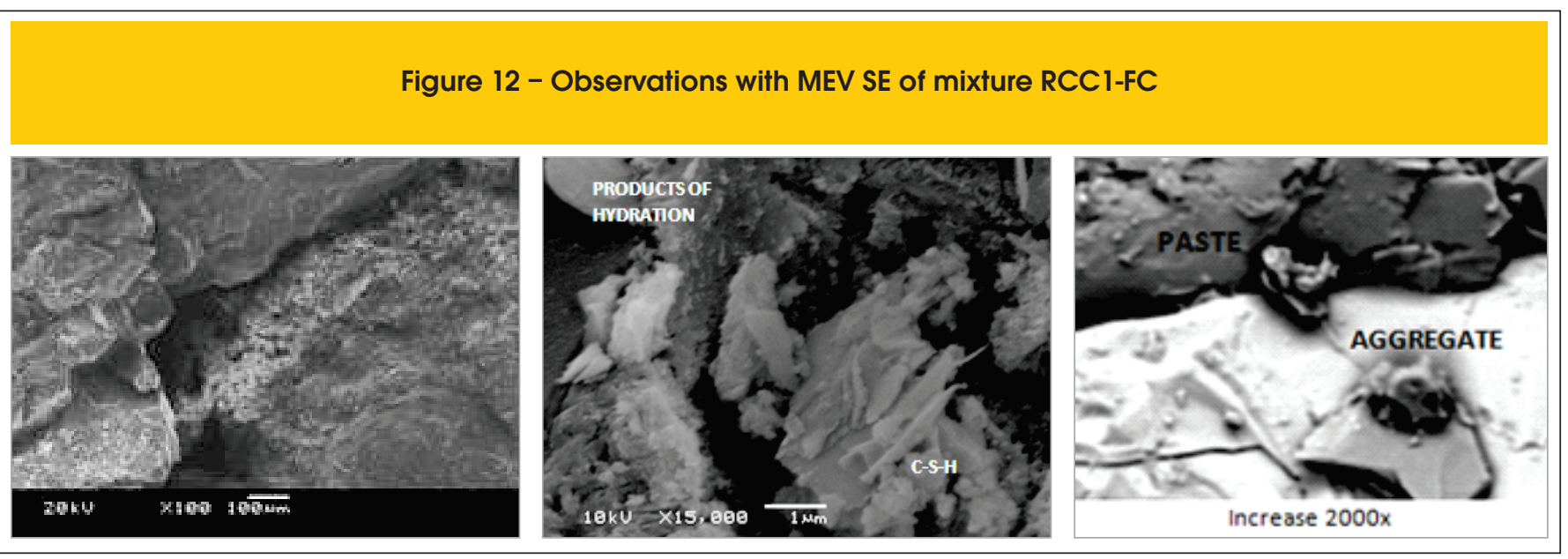


erence concrete. This increase was caused by the impermeability of the milled aggregates surface due to the presence of asphalt film around them. The concrete that showed higher w/c was the RCC1-FS (incorporating the milled fraction in the sand range), followed by RCC1-FT (with total fraction incorporation), which resulted in more porous samples. Therefore, there is a clear suspicion that the presence of milled fine fraction requires higher content of water for compaction; once maintained the cement consumption, there is a drop of strength;

- Any of the dry concrete (studied) incorporating RAP have expressive reduction in both indirect tensile and flexural strength and, regardless of the amount and particle size of the RAP band, accompanied of decrease in values of modulus of elasticity;

- The concrete with total RAP fraction incorporated was the most affected one in relation to the reduction in the values of modulus of elasticity;

In the milled concrete incorporation, rupture was visibly differentiated, and the specimens do not split immediately after the peak load to the rupture; conversely, the concrete without RAP fractured more abruptly at the maximum load of rupture;

- According to microscopic analysis, the RAP-RCC concrete features are more empty, a fact that apparently interfered with the decrease in specific weight values;

- Microscopic observations revealed that even with RAP aggregates, there was clear formation of the hydration products of Portland cement in the RCC mixtures;

- SEM images were important because it allowed the observa- tion of the interface between the paste and RAP aggregate. Adhesion failures were evident in that zone; the observations showed that for the dry concrete the amount of paste is not enough to involve the aggregates (low-mortar level);

- The RCC2 concrete (river sand) showed higher porosity compared to RCC1 (with industrial sand), but both have had better quality of bond between aggregate and cement paste;

- In the present RCC1-FM concrete, it was observed during the analysis with SEM, the presence of pores with rounded shapes, caused by the presence of trapped air in the mixture; in addition, the RAP aggregate was not broken with the rupture of the specimen, which was reflected in the results of tensile strength and modulus of elasticity: both parameters were higher for the mixture;

- The microstructural features observed for RCC1-FC are the presence of large and rounded pores and coarse aggregates with relief, which allows concluding that the rupture was given in the cement paste and not in the aggregate.

- Microscopic analyzes allowed to observe largest concrete porosity in the RCC1-FS, which was consistent with the higher moisture content observed.

As for the mechanical results observed, it can be conclude that, although the specific RAP incorporations decreased the strength of the dry concrete, affecting all mechanical parameters, and apparently increasing the porosity of the mixtures. Still, this is a material which can be used as sub-base and base floor (underneath layers of concrete or asphalt pavements) compared to other traditional materials such as cement treated crushed stone, because their

Figure 13 - Micrographs obtained by stereomicroscopy. (a) RCC1 - magnified 20X; (b) RCC2 - magnified 8X;

(c) RCC1-FT - magnified 8X; (d) CCR1-FS - magnified 25X;

(e) CCR1-FM - magnified 25X; (f) RCC1-FC - magnified 10X.
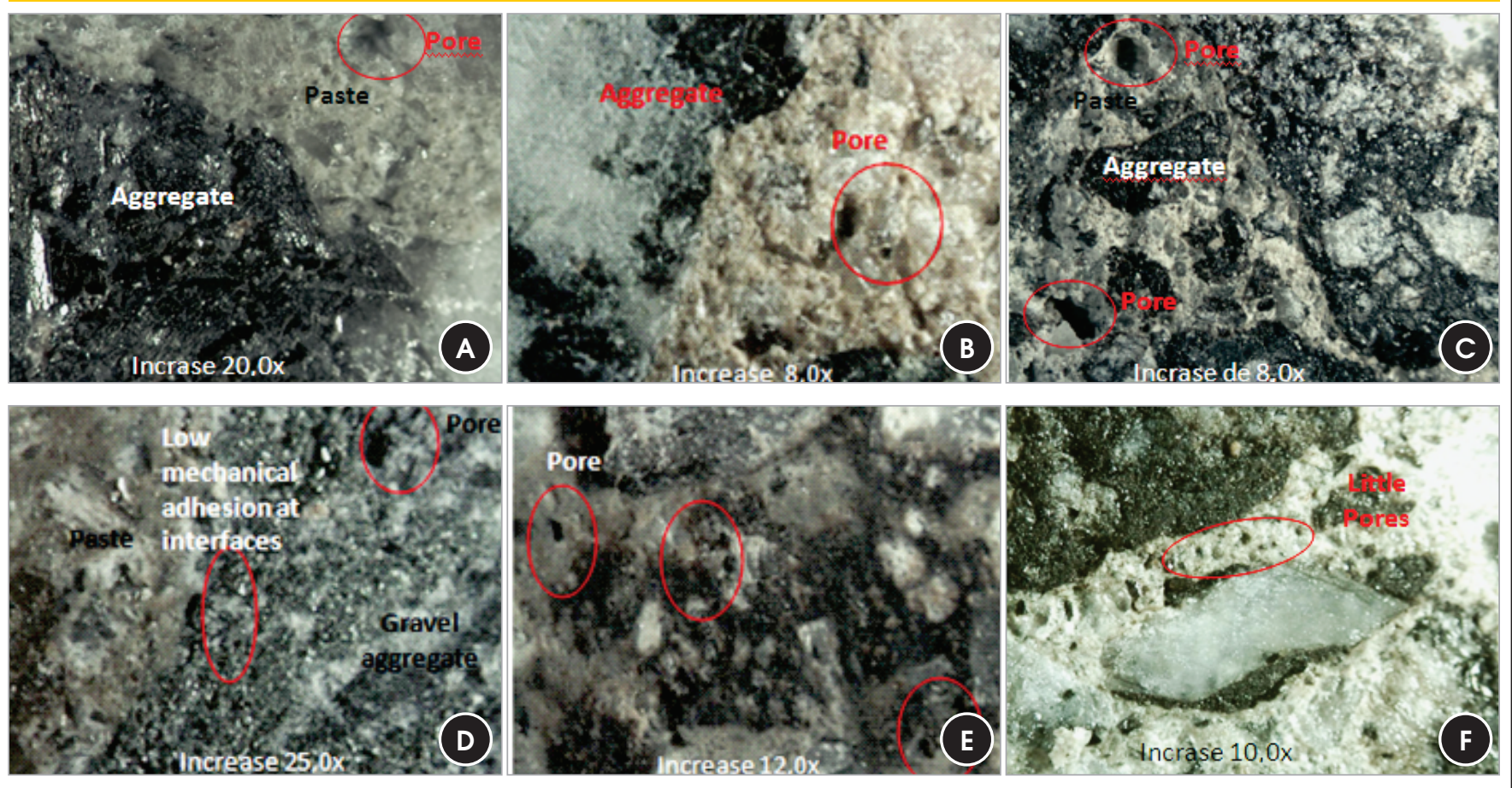
properties are even better compared to others. This conclusion is significant because the results of the study show that the incorporation of RAP to prepare RCC bases is quite feasible, and that, also, the resulting material is of higher quality than other conventional materials for pavement bases. Finally, it is shown a possibility of sustainable management of milling products with its use in the preparation of dry concretes.

\section{Acknowledgements}

The main and middle authors have had their project sponsored by the National Council of Scientific and Technological Development (CNPq-MCT-Brazil) through process 473498/06-5. Authors are grateful to the Eletronic Microscopy Center (CME) as well as to the Pottery Laboratory (LACER) of the Federal University of Rio Grande do Sul at Porto Alegre for the given support to the microscopic analysis.

\section{References}

[01] FEDERAL HIGHWAY ADMINISTRATION. Reclaimed Asphalt Pavement. Disponível em: <http://www.tfhrc.gov/hnr20/recycle/waste/rap131.htm>. Acesso em 03/07/2009.

[02] DELWAR, M., FAHMY, M., TAHA, R. Use of reclaimed asphalt pavement as an aggregate in Portland cement concrete. ACI Materials Journal, v. 94, 3, 1997, p.251-256.

[03] HUANG, B., SHU, X., LI, G. Laboratory investigation of Portland cement concrete containing recycled asphalt pavements. Cement and Concrete Research, 35, 2005, p.2008-2013.

[04] HUANG, B., SHU, X., BURDET, E., G. Mechanical properties of concrete containing recycled asphalt pavements. Magazine of Concrete Research, 58 (5), 2006, p.313-320.

[05] HOSSINEY, N., WANG, G., TIA, M., BERGIN, M. J. Evaluation of concrete containing RAP for use in concrete pavement. Proceedings of the Transportation Research Board Annual Meeting (Cdrom), Transportation Research Board, Washington, D.C., 2008, 13 p.

[06] SACHET, T.; BALBO. J.T.; PINTO, P.C.; MUGAYAR, A.N.; ALBUQUERQUE, M.C.F. Incorporação de fresado asfáltico em concreto compactado com rolo.

Proceedings of the 51th Brazilian Concrete Conference (Cdrom), IBRACON, 2009, Curitiba.

[07] AMERICAN CONCRETE INSTITUTE. Roller Compacted Concrete - Authorized Reprint form Concrete International: Design and Construction. v.9, 2, 1987, 55p.

[08] PITTMAN, D. W., RAGAN, S. A. Drying shrinkage of roller-compacted concrete for pavement applications. ACl Materials Journal, vol. 95, 1, 1998, p.19-26.

[09] ASSOCIAÇÃO BRASILEIRA DE NORMAS TÉCNICAS. NBR7222: Argamassa e concreto - Determinação da resistência à tração por compressão diametral de corpos-de-prova cilíndricos. Rio de Janeiro, 1994, 3p.

[10] AMERICAN SOCIETY FOR TESTING OF MATERIALS. C78-08: Standard Test Method for Flexural Strength of Concrete (Using Simple Beam with Third-Point Loading), 2008.

[11] SACHET, T.; ALBUQUERQUE, M.C.F.; BALBO. J.T.; SANSONE, C.E. Investigation of resistance and fracture parameters for compacted concrete with incorporation of reclaimed asphalt pavement. Int. J. of Pavements, v. 10, pp. 83-93, 2011. 